University of Wollongong

Research Online

Faculty of Social Sciences - Papers (Archive) Faculty of Arts, Social Sciences \& Humanities

$1-1-2016$

Gendered responses to the 2009 Black Saturday bushfires in Victoria, Australia

Joshua Whittaker

Melbourne Institute Of Technology

Christine Eriksen

University of Wollongong, ceriksen@uow.edu.au

Katharine Haynes

Macquarie University

Follow this and additional works at: https://ro.uow.edu.au/sspapers

Part of the Education Commons, and the Social and Behavioral Sciences Commons

Research Online is the open access institutional repository for the University of Wollongong. For further information contact the UOW Library: research-pubs@uow.edu.au 


\title{
Gendered responses to the 2009 Black Saturday bushfires in Victoria, Australia
}

\begin{abstract}
This paper presents findings from a gendered analysis of resident responses to the 2009 Black Saturday bushfires (wildfires) in Victoria, Australia. One hundred and seventy-three people lost their lives in the bushfires and more than 2000 houses were destroyed. Previous research on Black Saturday has largely focused on issues of resident preparedness and response, with limited consideration of the role of gender in household decisions and actions. This paper examines the gendered dimensions of risk awareness, preparedness and response among households affected by the bushfires. Data were collected through indepth interviews with over 600 survivors and a questionnaire of 1314 households in fire-affected areas. Analysis revealed that women more often wanted to leave than men, who more often wanted to stay and defend property against the bushfires. Nevertheless, findings suggest that broad-brush characterisations of staying to defend as a masculine response and leaving as a feminine response are misguided. Although some women expressed a strong desire to leave, others were resolute on staying to defend. Equally, while some men were determined to stay and defend, others had never considered it an option. Despite this, the research identified numerous instances where disagreement had arisen as a result of differing intentions. Conflict most often stemmed from men's reluctance to leave, and was most apparent where households had not adequately planned or discussed their intended responses. The paper concludes by considering the degree to which the findings are consistent with other research on gender and bushfire, and the implications for bushfire safety policy and practice.
\end{abstract}

\section{Keywords}

victoria, responses, australia, 2009, black, saturday, bushfires, gendered

\section{Disciplines}

Education | Social and Behavioral Sciences

\section{Publication Details}

Whittaker, J., Eriksen, C. \& Haynes, K. (2016). Gendered responses to the 2009 Black Saturday bushfires in Victoria, Australia. Geographical Research, 54 (2), 203-215. 


\section{Gendered responses to the 2009 Black Saturday bushfires in Victoria, Australia}

Joshua Whittaker ${ }^{1,4^{*}}$

Christine Eriksen²

Katharine Haynes 3,4

1: Centre for Risk and Community Safety, School of Mathematical and Geospatial

Sciences, College of Science, Engineering and Health, RMIT University, Melbourne 3000, Australia

2: Australian Centre for Cultural Environmental Research, School of Geography and Sustainable Communities, Faculty of Social Sciences, University of Wollongong, Wollongong 2522, Australia

3: Risk Frontiers - Natural Hazards Research Centre, Macquarie University, Sydney 2109, Australia

4: Bushfire and Natural Hazards Cooperative Research Centre, Australia

* Corresponding author

Phone: +61399252418

Fax: +61399252454

Email: joshua.whittaker@gmail.com

Abstract:

This paper presents findings from a gendered analysis of resident responses to the 2009 Black Saturday bushfires (wildfires) in Victoria, Australia. 173 people lost their lives in the bushfires and more than 2000 houses were destroyed. Previous research on Black Saturday has largely focused on issues of resident preparedness and response, with limited consideration of the role of gender in household decisions and actions. This paper examines the gendered dimensions of risk awareness, preparedness and response among households affected by the bushfires. Data were collected through in-depth interviews with over 600 survivors and a questionnaire of 1314 households in fire affected areas. Analysis revealed that women more often wanted to leave than men, who more often wanted to stay and defend 
property against the bushfires. Nevertheless, findings suggest that broad-brush characterisations of staying to defend as a masculine response and leaving as a feminine response are misguided. Although some women expressed a strong desire to leave, others were resolute on staying to defend. Equally, while some men were determined to stay and defend, others had never considered it an option. Despite this, the research identified numerous instances where disagreement had arisen as a result of differing intentions. Conflict most often stemmed from men's reluctance to leave, and was most apparent where households had not adequately planned or discussed their intended responses. The paper concludes by considering the degree to which the findings are consistent with other research on gender and bushfire, and the implications for bushfire safety policy and practice.

Key words: gender; bushfire; wildfire; preparedness; emergency response; evacuation; risk reduction

Andrew didn't want to leave. He wanted to stay and fight with the community. Our daughter got very anxious and was crying and wanting to leave. James [our son] was sort of in between that. He was getting anxious and he said 'I want to leave'. The cloud of smoke finally descended on us and so we were in it - in the ash-and I couldn't get Andrew to leave. I thought, 'Well, what do I do?' I walked out of the clubhouse and a SES [State Emergency Service] man came along. He said, 'You need to go. You need to get out because if you stay behind, there will be nobody left to save you'. I ran out and said to Andrew, 'The SES have told us to leave. Put down the hose and let's go'. And finally, he did. 


\section{Introduction}

74 Research has shown that women and men tend to respond differently to bushfire (Cox, 1998; Hoffman, 1998; Proudley, 2008a; Eriksen et al., 2010; Haynes et al., 2010). Beth's account (above) of the 2009 Black Saturday bushfires in Victoria, Australia, highlights some of the common differences in how men and women tend to perceive, prepare for and respond to bushfire risk. ${ }^{1}$ Importantly, her account also provides insights into how gender relations influence household decisions and actions during bushfires. Her family had spent the evening and morning before the fire front arrived packing their cars and readying themselves to leave. Like many other local residents, they left their home when the bushfires hit the small town of Marysville, arriving at the local golf club a short time later. The golf club was believed by many to be a place of relative safety, but it too came under direct threat. As the fire front approached, Beth's husband joined others in attempting to defend the clubhouse. She pleaded with him to leave and, although their children were distressed and wanted to leave, it was only when they received authoritative directives from emergency service personnel that they left.

In the days preceding the bushfires Victorians had been warned to prepare for 'the worst [fire danger] day in the history of the state' (Premier of Victoria, John Brumby, cited in Moncrief, 2009). This prediction proved accurate with a record high maximum temperature of $46.4^{\circ} \mathrm{C}$ $\left(115.5^{\circ} \mathrm{F}\right)$ in Melbourne, record low humidity and strong winds throughout the state (Karoly, 2009). More than 400 bushfires started across the state of Victoria on Saturday 7 February 2009 (Figure 1), with most of the major conflagrations started by fallen power lines or arson (Teague et al., 2010). The speed, intensity and extent of the fires meant that many communities came under threat with little or no official warning. In line with official advice for all bushfires, most residents responded without direct assistance from fire services. 172 civilians lost their lives in the bushfires and one volunteer firefighter was killed by a falling 
tree limb during firefighting operations on 17 February (Blanchi et al., 2012). 2298 houses were destroyed (Crompton et al., 2010).

[Figure 1 about here]

This paper presents findings from a gendered analysis of resident responses to the 2009 Black Saturday fires in Victoria, Australia. Data were collected as part of a research project that involved in-depth interviews with more than 600 survivors followed by a mail questionnaire of 1314 households in fire affected areas (Whittaker et al. 2009a, 2009b). The paper reviews research on gendered dimensions of bushfire, before discussing the research questions and methods that were used to conduct this research. Results are presented from an analysis of the interview and questionnaire data, including findings related to women's and men's: awareness of bushfire risk; planning and preparation; intended responses; and actual responses to the fires. The paper concludes by discussing the degree to which the findings are consistent with other research on gender and bushfire, and the implications for bushfire safety policy and practice.

\section{Gender and bushfire}

It is increasingly clear from research internationally that women and men are exposed to risk in different ways and at different levels because of the everyday gender divisions of labour and gendered norms that underpin intended and actual patterns of disaster preparedness and response (Campbell et al., 2006; Bryant and Pini, 2010; Enarson, 2012; Eriksen, 2014a and 2014b). Women and men are variously at risk through, for example: the type of work they do; distributions of power (and thus decision-making processes) domestically, locally and 
123 officially; the need to care for children, elderly or disabled people; societal pressure to

124 perform certain roles; their economy, class and ethnicity (Enarson, 2012; Eriksen, 2014a and 2014b). While gendered dimensions of bushfire on the surface often appear to reinforce women's vulnerability to bushfire more so than for men, Eriksen (2014a) highlights the

127 increased vulnerability of both women and men because of the activities they tend to perform

128 before, during and after bushfires. Many women deprioritize bushfire preparation in the 129 context of other pressing issues in everyday life, while societal pressure sees men attempt to 130 perform protective roles when the fire threatens that many have neither the knowledge nor 131 ability to fulfill safely.

133 Poignant statistics that drive home this message of gendered vulnerability in the context of 134 bushfires are those of the activities performed by women and men at time of death during 135 bushfires historically (Haynes et al., 2010). From a total of 552 bushfire-related deaths in 136 Australia between 1900 and 2008, 373 were men (67 percent), most of whom died outside 137 while attempting to protect assets (46 percent of 277 total male deaths where the activity at 138 time of death was known) (Haynes et al., 2010). Whilst male fatalities decreased during the 139 second half of this time period from 77 percent (of 292 total deaths from 1900-1954) to 57 140 percent of all deaths (of 260 total deaths from 1955-2008), there has been an increase in the 141 proportion of women who died in bushfires since 1955 from 16 percent (of 292 total deaths 142 between 1900-1954) to 38 percent of all deaths (of 260 total deaths between 1955-2008), 143 most of whom died while sheltering or evacuating. Haynes et al. (2010) highlight that the 144 changing gender trends seen over the last 100 years or so are likely to be related to shifting 145 social circumstances influencing the work people do and the locations in which they live. This 146 has a direct impact on the activities engaged in at the time of death. For example, fewer men 147 work outdoors today than in 1900 , whilst widespread ownership of cars nowadays provide the 
means to travel during times of danger. Blanchi et al.'s (2014) examination of environmental circumstances surrounding bushfire fatalities in Australia from 1901-2011 aligns with Haynes et al.'s (2010) findings on the significant gender differences in the circumstances and temporal distribution of fatalities. The gender distribution of the Black Saturday fatalities is similar to the trends seen in more recent fires. 58 percent of the 172 people who died (149 adults and 23 children under the age of 17) were male and 42 percent were female. Blanchi et al. (2014) additionally identified that fire weather severity and proximity to forests are strong qualifiers of fatalities, 'with a significant shift from open air fatalities at low FFDI's [Forest Fire Danger Index] to a dominance of inside structure deaths at FFDI's greater than 100' (p. 198 ) and "with over $78 \%$ of fatal exposures occurring within $30 \mathrm{~m}$ and $85 \%$ within $100 \mathrm{~m}$ of the forest edge' (p. 201).

When gendered dimensions of risk engagement are contextualized in everyday gender roles and traditions and compared with bushfire fatality trends during the last century, a frightening correlation emerges between women's and men's activities at time of death historically and intended plan of action during bushfires today. In short, 'most women intend to evacuate, women predominantly die while attempting to evacuate or sheltering passively; most men intend to stay and defend, men mostly die outdoors attempting to defend assets' (Eriksen, 2014a, p. 39). The 2009 Black Saturday bushfires highlight that bushfire risk information, engagement and education initiatives have not managed to curb this trajectory of bushfire fatalities. This research aims to re-analyse the quantitative and qualitative data collected following the 2009 Victorian bushfires to better understand the gendered dimensions of bushfire risk and response on Black Saturday. In doing so, the research explores, for the first time, how gender influenced planning, preparedness, intended responses and actual responses to the fires. 


\section{$174 \quad$ Research methods}

175 Data were collected as part of the Bushfire Cooperative Research Centre's (CRC) Research

176 Taskforce following the 2009 Black Saturday bushfires. The Taskforce was established to

177 provide the Victorian Bushfires Royal Commission and Australian fire and emergency

178 services with an independent analysis of the factors that contributed to the fires' severity and

179 impacts. The scope of the research was determined by the Bushfire CRC and Victoria's

180 Country Fire Authority (CFA) and Department of Sustainability and Environment (DSE; now

181 Department of Environment Land Water and Planning). The Taskforce covered three areas of 182 research: fire behaviour, human behaviour and community safety, and building and planning 183 issues.

This paper presents findings from an analysis of data collected as part of the human behaviour and community safety research component. The research examined residents' planning and

187 preparedness, decisions and responses to the 7 February 2009 fires through semi-structured 188 interviews with residents followed by a mail questionnaire of households within fire affected areas. An earlier study (Whittaker et al., 2009a; 2009b) analysed the data to address broader questions related to household preparedness and response, with no detailed gender analysis undertaken. The aim of the secondary analysis was to identify similarities and differences in

192 the preparedness and responses of women and men.

Semi-structured interviews

195 A team of researchers began interviewing residents affected by the fires on 12 February 2009, 196 with more than 600 interviews conducted over a 12-week period. An interview guide was 197 developed comprising questions about residents' planning and preparation, information and 
warnings they received, their intended and actual responses to the fires, and what they would

199 do in future fires (see McLennan et al., 2013). Interviews were digitally recorded with the

200 permission of interviewees and subsequently transcribed. The qualitative data analysis

201 software NVivo v.10 was used to manage the large volume of data and to assist the analysis. A

202 coding framework was developed, setting out the categories into which segments of interview

203 text could be grouped to enable closer analysis and comparison.

204

205

Mail questionnaire

206 The mail questionnaire comprised a range of questions concerning community safety issues,

207 including awareness of bushfire risk before Black Saturday, the information and warnings

208 people received, actions taken to plan and prepare, intended and actual responses to the fires,

209 effects of the fires on households, and basic demographic information. Questionnaires were

210 mailed in October 2009 to 6000 addresses in areas affected by the bushfires. Addresses that

211 fell within the 'burnt area', as defined by DSE, were extracted from the Vicmap database. ${ }^{2}$

212 Residents were given three weeks to return the questionnaire. They were encouraged to

213 complete the questionnaire via a series of radio interviews, newspaper articles and flyers left

214 at recovery centres. A response rate of 25 per cent was obtained, with 1314 questionnaires

215 received from residents within the major fire complexes. This figure excludes 699

216 undeliverable surveys that were returned. It is likely that more undeliverable surveys were not

217 returned to researchers (e.g. where residents had relocated or perished). Men and women were

218 more or less equally represented in the sample (53\% women, $n=642 ; 47 \%$ men, $n=574)^{3}$ and

219 the majority of respondents (59\%) were aged between 35 and 54.

221 The data analysis software SPSS v.17 was used to re-analyse the quantitative data and run

222 Pearson's chi-squared test of contingencies (Bryman, 2008) to evaluate whether questionnaire 
components, such as perceptions of preparedness, and intended and actual responses were

224 related to gender (for more details of the statistical approach see Allen and Bennett, 2008).

225 Although other demographic data were collected from participants, the analysis reported in

226 this paper focused on gender only.

228 Ethics approval for the research was obtained from RMIT University's Human Ethics

229 Research Committee, with measures taken to ensure the safety and rights of participants and

230 researchers. Anonymity was assured to all participants, who gave their consent for aggregated

231 data and quotes to be used in publications.

233 Findings from the qualitative and quantitative components of the research are presented

234 together below. In this paper, findings from the qualitative research are used to contextualise

235 and provide deeper insights into findings derived from the quantitative research. Quotes are

236 presented to give voice to the survivors of Black Saturday and to provide meaning to the often

237 decontextualised quantitative findings. Except where noted otherwise, quotes were selected to

238 be representative of gender patterns identified in the qualitative analysis.

\section{Research findings}

241 Pre-fire awareness of bushfire risk

242 The questionnaire results suggest high levels of bushfire awareness before Black Saturday. It

243 should be recognised that hindsight bias - where outcome information influences respondents'

244 recollections of their prior knowledge or beliefs (Bradfield and Wells 2005) - is likely to have

245 influenced these results. More than three quarters (78\% of 1193) of all respondents reported

246 that they had previously thought it likely or very likely that a bushfire could occur in their

247 town or suburb. No significant differences were identified for male and female respondents in 
248 their pre-fire awareness. Around two-thirds (67\% of 1187) of all respondents indicated they

249 had perceived a high or very high level of threat. Slight gender differences were identified,

250 with male respondents more often having rated the threat as high or very high (men $71 \%$ of

251559 , women $64 \%$ of 628) and female respondents more often having rated the threat as low or

252 very low (women $35 \%$, men $28 \%$ ).

253

254 Analysis of the qualitative data did not identify clear differences between women and men's

255 pre-fire awareness of bushfire risk. Household location and past experience of bushfire appear

256 to exert a stronger influence on awareness (Whittaker et al., 2009a; 2013).

Planning and preparation

259 More than two-thirds of male (70\% of 530) and female (67\% of 594) respondents claimed to

260 have had a 'firm' plan for what they would do in the event of a bushfire. Similar proportions

261 reportedly discussed their plan with all members of the household (men $87 \%$ of 484, women

$26284 \%$ of 531), thought about what each person would need to do (men $77 \%$ of 402 , women

$26372 \%$ of 479$)^{4}$, and let neighbours know what they intended to do (men $52 \%$ of 432 , women

$26456 \%$ of 531). A minority of respondents reported having written down important things to do

265 and remember, with women (28\% of 499) slightly more likely to report having a 'written plan'

266 than men $(22 \%$ of 402$)$.

267

268 When asked to reflect on their level of preparedness for the Black Saturday fires, almost half

269 of the questionnaire respondents rated their preparedness as high to very high (45\% of 1189),

270 with the remainder assessing their preparedness as average (37\%) and low or very low (18\%).

271 Men (49\% of 563) were slightly more likely than women (41\% of 626) to rate their

272 preparedness as high or very high, with women (23\%) more likely than men (13\%) to 
273 consider their preparedness level as low or very low $\left[X^{2}(4, n=1189)=25.59, p=.000\right]$. Women

274 (78\% of 611$)$ more often than men (68\% of 550) said they had wanted to be more prepared

275 for the fires $\left[\mathrm{X}^{2}(1, \mathrm{n}=1161)=15.51, \mathrm{p}=.000\right]$. This was evident in an interview with a

276 woman whose husband had been intent on staying to defend, despite what she believed to be a

277 lack of preparedness:

278
I always knew this place wouldn't be safe if there was a bushfire. It's not prepared. We always talk about preparing it but we never do. And to prepare it we'd have to get - there's a lot of work throughout the year that we're trying to do anyway. But my husband's different. He'd stay and defend, whereas I just think, nah you don't do that, it's not worth it [...] So I guess being 'fire ready' involves a lot more, obviously. I suppose there are bits and pieces that I can see that I didn't realise that I would certainly hope to change [...] Gas bottles and gum trees have obviously been a drama. I wouldn't mind seeing those things changed...

Female, Marysville

Statements that there was nothing more that could have been done to prepare were more common in interviews with men, many of whom felt that the Black Saturday bushfires were so extreme that preparedness counted for little:

So really in terms of fire preparation, no. But nobody was expecting a firestorm. I mean, if it had just been a bushfire and it had just been some strong winds and some embers and all of that kind of stuff, I would have been quite happy to stay and fight it. 
300 Of course, there were examples of men who had reflected deeply on their lack of

301 preparedness and women who had not. However, what is apparent from the qualitative data, 302 and perhaps more important, is the tendency for men to speak about 'hard' preparations, such 303 as reducing fuel and setting up sprinkler systems, and for women to speak about 'soft'

304 preparations, such as planning household responses and measures to ensuring the safety of 305 children and other vulnerable household members.

\section{Intended responses}

308 Analysis revealed significant differences in men and women's intended responses $\left[X^{2}(7, n=\right.$ $3091134)=50.25, \mathrm{p}=.000]$. Men $(56 \%$ of 534) more often wanted to stay and defend throughout 310 a fire than women (42\% of 590), while women (23\%) more often than men (11\%) wanted to

311 leave as soon as they knew a fire was threatening. In terms of those who intended to "wait and 312 see' (an approach discouraged by fire authorities due to the increased risk of late and 313 dangerous evacuations or becoming trapped at an un-defendable property), men (11\%) were 314 more likely than women (7\%) to intend to wait until the fire arrived before deciding whether 315 to stay or leave, and women (20\%) were more likely than men (15\%) to intend to stay and 316 defend but leave if they felt threatened. Very few men or women said they had planned to 317 leave on all days of high fire danger, regardless of whether a fire had started (both $2 \%$ ).

319 Analysis of the qualitative data revealed that responsibilities for children, the elderly and 320 other vulnerable household members greatly influenced many people's intentions to leave. In 321 some cases, all members of the household planned to leave. In many cases, however, women 322 left with children and elderly household members, while men stayed behind to defend the 
house and property:

324

Our plan was: I leave with the kids and he stays and fights.

Female, Flowerdale

Male, Kinglake West

They were gone first thing that morning, even before the fire-because we knew it was going to be a hot day. She normally goes into town to her mother's, takes the kids straight away.

Male, Callignee

The interview analysis revealed a number of cases where members of a household disagreed over their intended responses to bushfires. A number of women reported that their intention for everyone in the household to leave conflicted with their male partner's intention.

My plan was to get the hell out-don't stay and defend the house 'cause it's going to go up. [...] We'd had a few arguments about it: 'No, no, he'd stay, he'd defend, we'd be able to grab buckets quick enough, we'd be able to do this ...'. But we haven't got tanks. The water would stop. He talked about getting a fire pump, but we never did. So I think that if it wasn't for us having to leave around 4pm ... maybe he would have done something dicky and stayed. 
I think I would have been screaming at him, 'cause I knew I wasn't fire ready. So that was our plan... Even though we haven't got insurance, you don't risk your life. You don't need to see something horrific.

353 Conflicting intentions were evident in a discussion between a husband and wife in St

354 Andrews. While the wife discussed the family intention to leave, if they could, the husband 355 interjected and stated that his plan was to stay: Female: Not written, but if we could leave with the animals we would. But if there was any doubt that we couldn't get out, we weren't going. We didn't want to stay but we've got the animals to care for. Male: No. My plan was to stay, by myself. And they were going to go. That happened last time. They all went and they wanted me to go, but I said: 'I'm staying, because I want to keep the house'.

Similarly, another interviewee recounted being told by a volunteer firefighter that his house was defendable, which led to disagreement with his wife: made the decision that I would stay because I didn't want to see the house go and I knew she had to go because of her asthma. So after a bit of yelling at each other, she 

have a house.

Less commonly, women were able to convince their male partners to leave or stay away from their property. A man in his 70s was in Melbourne when the fires threatened his Strathewen property:

She made me stay, yeah. The only time I really listened to my wife! [...] Yes, I'm glad I listened to her. I would have maybe saved something [if I went to defend the house] but... there was no place where you can save yourself.

Actual responses

Reflecting the data on intended responses, there were significant differences between women's and men's actual responses to the fires $\left[X^{2}(7, n=1149)=54.92, p=.000\right]$. Men (62\% of 548) more often stayed to defend their homes and properties than women (42\% of 601), who more often left before or when the fire arrived (women 54\%, men 35\%). A small proportion of women $(5 \%)$ and men $(3 \%)$ reported that they sheltered inside a house or some other structure, in a vehicle, or somewhere outside.

394 Those who left:

395 As noted above, a greater proportion of women (54\%) left before or when the fires arrived 396 than men (35\%). For women (55\% of 324) and men (49\% of 189), the most common reasons 397 for leaving were believing it was too dangerous to stay and defend, and seeing or smelling 
398

399

400

401

402

403

404

405

406

407

408

409

smoke nearby (women 35\%, men 28\%). Similar proportions of women (26\%) and men (24\%) left because there was fire in the vicinity of their property, and to remove other household members from danger (women 27\%, men 25\%). However, results indicate that women (35\%) more often left on the advice of others. They were far more likely than men (13\%) to leave because relatives, friends or neighbours told them to or on the advice of police, fire or emergency services (women 14\%, men 8\%).

Analysis of the interview data also revealed evidence of women being more receptive to advice from relatives, friends, neighbours and emergency services. One interviewee described her husband and son's advice to leave as a 'gentlemanly' thing to do, while another noted that her husband's advice was potentially dangerous:

\section{I suppose it was a very gentlemanly thing to do for my son and husband to say, you} know, 'leave now'. I guess it was a very protective sort of thought, about keeping us safe, whereas they may have been in danger themselves. So it was a gentlemanly thing, a courtesy thing I suppose.

Female, Labertouche Pete told me to put the kids in the car. But if I'd reversed out it would have engulfed us. Female, Maiden Gully In terms of the timing of people leaving, similar proportions of men (47\% of 201) and women (49\% of 345) left between an hour or more before the fires arrived in their town or suburb. However, women (35\%) more often left in the hour leading up to the fire than men $(27 \%)$ and men $(26 \%)$ more often left once the fire had arrived than women did $(22 \%)$. The majority of 
423 women $(57 \%)$ and men $(53 \%)$ believed they had left late or very late, with between one-

424 quarter and one-third deeming themselves to have left early or very early (women $30 \%$, men

$42527 \%$ ). No significant differences were observed in perceptions of the danger encountered

426 when leaving, with the majority of men (80\% of 218$)$ and women (78\% of 354) rating the

427 danger as high or very high. One-third of women (75\% of 344) and men (74\% of 213) who

428 left before or when the fires arrived indicated that they would take the same action in a future

429 bushfire.

430

431 One interviewee explained how people could pressure others into responses they had not

432 intended or prepared for.

433

She said she was lucky because she was by herself, she could make her own mind up. She felt as though she was overreacting. She said 'I felt stupid driving out to Buxton. Everyone is going to say 'What the hell is the matter with you over reacting?' She said down in the town she did see some couples arguing... The bloke says, 'No, I'm going to stay on the roof watering' and the woman says, 'Let's go, I want to go' and he says, 'Well, you go'. And so she said that's what saved her, the fact that she didn't have to argue with anyone.

However, highlighting the diversity of experiences, there were cases where men who intended to stay and defend ended up leaving to remain with their partner to ensure their safe evacuation. 
leave, and then in the end I wasn't happy for her to drive on the road anyway. I

453 Those who stayed to defend:

454 Consistent with the data on intended responses, a greater proportion of men (62\% of 548) stayed to defend their homes and properties than women (42\% of 601). Of these, the majority stayed throughout the fire and actively defended (men 79\%, women $74 \%$ ), with a smaller but considerable proportion leaving once they felt the danger was too great (men 18\%, women $22 \%)$. The remainder stayed to defend but did not experience fire at their home or property (men 3\%, women 4\%).

The main reason men (86\% of 342) and women (78\% of 249) stayed with their home during

462 the bushfires was to protect their homes and property. However, women (17\%) were more

463 likely than men (9\%) to stay because they felt it was not safe to leave or because their

464 attempts to leave were unsuccessful. While men (35\%) more often reported feeling safe than women $(23 \%)$, a considerable proportion still felt unsafe while staying with their house (men $29 \%$, women $36 \%)$. Similarly, men (85\%) were more likely than women $(71 \%)$ to report that

467 they had felt confident that they could protect themselves and others $\left[X^{2}(3, n=645)=33.45\right.$, $468 \mathrm{p}=.000]$, as well as their house and property (men $75 \%$, women $59 \%)$ from the fires $\left[\mathrm{X}^{2}(3, \mathrm{n}\right.$ $469=628)=22.38, \mathrm{p}=.000]$.

471 Consistent with the results presented above, women (68\%) were found to be less likely to 472 want to stay and defend against future bushfires than men $(83 \%)\left[X^{2}(1, n=642)=20.15, p\right.$ 

I wouldn't change a thing. I would always stay and defend. I would only be a little bit better prepared next time.

We thought it was only going to last for 20 minutes, you know, give or take a few. I was willing to be flexible there but nothing compared to what it did. I would never recommend anybody stay for a fire, ever. You can't - I don't know how you can sit there and wait not knowing if you are going to die or not without going absolutely insane.

The data demonstrate that the decision to stay or leave is rarely straightforward. An interviewee who left to take her children to safety explained her conflicting desire to stay with her husband to defend their home against future fires, despite acknowledging the substantial benefits of her actions on Black Saturday:

I think I'd be more inclined to stay in the respect that I think my husband would have been better off having someone to help him and I felt a bit guilty about the fact that he was on his own here. But at the same time my children seemed to be a little less traumatised because I actually got them out of the area. They didn't have to see the flames. [...] I have friends in that situation and their kids are very clingy and they're having a few little issues, whereas my kids sort of seem to be okay with that. So yeah, maybe if I could get the kids out, I'd 
anything as disastrous as that in our lifetime, hopefully.

Those who took shelter:

503 No statistically significant differences were identified for male and female respondents who 504 took shelter. A small proportion of men $(5 \%, n=17)$ and women $(3 \%, n=28)$ did not actively defend the house or property but stayed throughout the fire and took shelter. Men $(55 \%, n=9)$ most often sheltered somewhere outside (vs. women $32 \%$, $n=9)$, while women $(39 \%, n=11)$ more commonly sheltered inside the house (vs. men $29 \%, \mathrm{n}=5$ ). The remainder sheltered in a structure other than a house or a vehicle (women $29 \%, \mathrm{n}=17$; men $18 \%, \mathrm{n}=12$ ).

There were a number of reasons why residents who took shelter during the fires stayed at their

511 homes and properties. Similar proportions stayed because they wanted to protect their house and property (men $38 \%, \mathrm{n}=5$; women $32 \%, \mathrm{n}=7$ ) or because it was too late to leave (men $15 \%$,

$513 \mathrm{n}=2$; women $18 \%, \mathrm{n}=4)$. Women $(41 \%, \mathrm{n}=9)$ were more likely to stay and take shelter

514 because their attempts to leave were unsuccessful (vs. men 23\%, $\mathrm{n}=3$ ).

516 Men $(67 \%, \mathrm{n}=10)$ more commonly reported feeling unsafe or very unsafe while sheltering 517 than women $(47 \%, \mathrm{n}=10)$, who more often said they felt neither safe nor unsafe (women $38 \%$, $518 \mathrm{n}=8$; men $20 \%, \mathrm{n}=3$ ). This is probably because men more often sheltered outside - where they

519 were more likely to be exposed to extreme heat, wind, smoke, embers and flames - while 520 women more often sheltered in the relative safety of the house. Most did not feel confident 521 that they could protect themselves and others while sheltering (men 63\%, $\mathrm{n}=10$; women $52 \%$, $522 \mathrm{n}=13$ ); much less protect their house and property (men 75\%, $\mathrm{n}=12$; women $87 \%, \mathrm{n}=21$ ). 
524 There was a tendency for women to shelter inside, often caring for children and other

525 vulnerable household members, and for men to shelter outside, often attempting to defend

526 against the fire or monitor its progress. However, analysis of the interview data revealed

527 considerable variation among men and women's experiences of sheltering.

The kids have got their own lounge room, and all the bedrooms go off that, so we closed all the doors so there were no exposed windows and made the kids and dogs sit in the lounge room and we said: 'Now stay there and don't move. No matter what, we will come and check on you'. That was the hardest part, the kids. My youngest daughter was freaking, saying: 'Mum, we are going to die aren't we?' and I said 'No we are not love. Sit in here, stay calm, let us do our job and we won't die.

We had been fighting it for a few hours and we were tired. [...] I dropped to the ground and my uncle put the hose on me because he thought I had passed out, but it was like I was dry, my body dried out [...] So he just doused me with water and I just stayed on the ground for five or ten minutes and just breathed into the wet towel. And the oxygen level on the ground was a lot easier for my

546 Most of those who stayed and sheltered through the fires said they would not take the same 547 action in a future bushfire (women $60 \%, \mathrm{n}=15$; men $53 \%, \mathrm{n}=9$ ). While some did believe that it 
was safe for them to shelter without defending, qualitative responses suggest that in the future

549 most respondents would attempt to leave early or actively stay and defend their house and 550 property instead. However, some noted that when fires threaten with little or no warning, 551 seeking shelter may be the only option.

\section{Discussion}

554 Findings from the gendered analysis of the mail questionnaire and in-situ interview data collected after the Black Saturday bushfires highlight both similarities and differences in how women and men perceive, prepare for and respond to the threat of bushfire. It is important to note that while patterns or tendencies were identified, there was no absolute gender divide.

558 However, findings from the analysis of interview data in particular provide insights into how

559 risk and response are negotiated within households, with gender relations often playing a key 560 role.

562 Findings suggest similar levels of pre-fire risk awareness of men and women. Slight

563 differences were identified for planning and preparation, with women tending to rate their

564 level of preparedness marginally lower and more often having a written plan than men.

565 Perhaps most significantly, women more often indicated that they could have been better 566 prepared and wanted to be more prepared for future bushfires. This suggests that bushfire 567 awareness and education programs designed specifically to engage and meet the needs of 568 women may be an effective way to increase household planning and preparation in at-risk 569 communities (see also Eriksen, 2014b).

571 As noted above, analysis of intended responses reinforces findings from other studies that 572 suggest men more often intend to stay and defend and women more often want to leave early 
573 (Proudley, 2008a; Eriksen et al., 2010; Haynes et al., 2010; Eriksen, 2014a). Nevertheless,

574 and although defending has been characterised as a masculine response (Tyler and Fairbrother,

575 2013), a considerable proportion of women (42\%) intended to stay and defend. Equally,

576 almost half of all men intended to leave before they were threatened.

578 Gender relations appear to play a far more significant role in actual responses to bushfires.

579 Trends in actual responses to the Black Saturday fires broadly aligned with those for intended

580 responses, with men more often staying to defend and women more often leaving. Again,

581 significant proportions of women defended (42\%) and around one-third (35\%) of men left.

582 Importantly, women were found to be more likely than men to leave on the advice of relatives,

583 friends, neighbours and emergency services (see also Proudley, 2008b). Again, this suggests

584 that messages specifically designed for and communicated to women may be effective in

585 encouraging early evacuations. However, it may also mean that some women may be more

586 receptive to poor advice, ultimately exposing them to greater danger.

588 Reasons people stayed with their homes during the fires reveal distinctive gender differences.

589 Men more often stayed because they wanted to protect their home and property (although this

590 was still a major reason for women), while women were more likely to stay because they

591 thought it was not safe to leave or because their attempts to leave were unsuccessful. Given

592 this, it is perhaps not surprising that women tended to feel less confident than men that they

593 could protect life and property. Similarly, women who stayed to defend were significantly

594 less likely than men to say they would defend against future bushfires. A previous analysis of

595 the same dataset (Whittaker et al., 2013a) reported that $75 \%$ of respondents who stayed to

596 defend said they would take the same action in a future bushfire (compared with $68 \%$ of

597 women and $83 \%$ of men in this analysis). This difference highlights the importance of even a 
basic gendered analysis.

599

600 Analysis of the qualitative data provides insights into how decisions about bushfire response

601 were negotiated within the household. In some households decisions were relatively

602 straightforward, with general agreement on each person's response. In households where

603 children were present, women often left with the children while men stayed to defend.

604 However, cases where disagreement was evident were common. In these instances, women

605 tended to be more concerned about risks to life, whereas men often claimed they had no other

606 option than to stay and defend the house and assets (Parkinson, 2011; Parkinson and Zara,

607 2011; Eriksen, 2014a). Disagreements were most apparent where people had not adequately

608 planned or discussed their response with other household members, as well as in situations

609 where plans changed at the last moment. These disagreements most often stemmed from

610 men's reluctance to leave. While some men discussed and negotiated their responses with

611 their partners and other members of the household (staying or leaving), others appear to have

612 seen themselves as relatively autonomous decision-makers. This is evident in Beth's story,

613 which begins this paper, where her husband decides to stay and defend the golf clubhouse

614 against his family's wishes. Ultimately, it is the authority of the emergency services that 615 persuades him to leave.

616

617 It is important to recognise that official bushfire safety policy was modified after Black

618 Saturday, due largely to the recommendations of the 2009 Victorian Bushfires Royal

619 Commission (Teague et al., 2010). Key among these changes was the revision of Fire Danger

620 Ratings to include a category beyond 'Extreme'. This led to the development of the 'National

621 Framework for Scaled Advice and Warnings to the Community' and the introduction of the

622 'Catastrophic / Code Red' rating (see Whittaker et al., 2013b). In Victoria, the CFA 
623 developed 'scaled advice' to more clearly communicate what residents can expect, and what

624 they should do for different levels of fire danger (CFA, 2015). Residents are advised that

625 homes are not designed or constructed to withstand fires burning under catastrophic

626 conditions, and that leaving high bushfire risk areas the night before or early in the day is

627 always the safest option. There has been a marked shift in the advice provided by fire

628 authorities to emphasise the risks to life associated with staying to defend and the relative

629 safety of 'leaving early'.

630

631 The extent to which this shift has altered intentions and actions amongst Australian residents

632 post-2009 is not known. At the time of writing, there has not been a subsequent bushfire of

633 the scale or severity of Black Saturday in Victoria or elsewhere in Australia. A survey of

634 householder preparedness in Australia during the 2012-2013 fire season $(n=516)$ found that

635 significantly more men (61\%) than women (22.5\%) intended to stay and defend their property

636 (Eriksen, 2014a, p.28), and that women (60\%) more often expressed a desire to leave as soon

637 as a bushfire was threatening or orders to evacuate were given than men did (25\%). These

638 findings suggest even greater disparity between women and men's intended responses and

639 emphasises the ongoing need to examine and accommodate gendered dimensions of risk

640 perceptions, preparedness and responses (intended and actual) in different regions,

641 jurisdictions and communities.

642

643 Conclusion

644 This paper has examined gendered dimensions of bushfire risk awareness, preparedness and

645 response among residents affected by the 2009 Black Saturday bushfires. The findings

646 presented largely support past research on gender and bushfire, which has identified

647 differences in women and men's perceptions of risk and intended and actual responses. This 
research found that women more often wanted to leave than men, who more often wanted to

649 stay. However, it is important to resist broad-brush characterising of staying to defend as a 650 masculine response and leaving as a feminine response. Just as there were women who

651 expressed a strong desire to leave, there were other women who were resolute on staying to 652 defend. Equally, while there were men who were determined to stay and defend, there were 653 others who never considered it as an option. Nevertheless, the research did identify instances 654 where disagreement had arisen as a result of differing intentions. These disagreements most 655 often stemmed from men's reluctance to leave, and were most apparent where households had not adequately planned or discussed their intended responses.

658 A number of findings suggest opportunities for enhancing community bushfire safety.

659 Women were found to have reflected more critically on their level of planning and 660 preparedness than men, suggesting opportunities to develop bushfire awareness and education 661 programs designed specifically to engage and meet the needs of women. Similarly, women 662 were found to be more receptive to advice from relatives, friends, neighbours and emergency 663 services, suggesting opportunities for tailoring and communicating information, advice and 664 warnings to women. People should also be encouraged to plan and discuss the intended 665 responses of all household members, including contingency plans, to avoid last minute 666 disagreements and decisions.

668 Finally, the findings in this paper highlight the benefits of designing community safety 669 initiatives tailored for women and men respectively, and that the popular belief in 'man as 670 autonomous decision-maker' only applied to a small minority of the research participants.

671 However, it is important to stress that because of the deeply ingrained gendered norms that 672 pervade Australian culture, many of the issues raised in this paper are unlikely to be resolved 
673 by outreach programs and information provision by emergency services alone. Cultural

674 change is needed more broadly for a lasting transformation to take place (Pease, 2010). This

675 is evident not only in the gendered dimensions of residents' intended and actual responses to

676 bushfires, as well as activities at time of death during bushfires historically, but also in the

677 systemic failing of society towards the domestic violence that followed the Black Saturday

678 bushfires (Parkinson, 2011; Parkinson and Zara, 2011; see also Enarson, 2012) and the

679 patriarchal structures that continue to challenge gender equity and awareness within

680 emergency management (Desmond, 2007; Pacholok, 2013; Eriksen, 2014a). The

681 acknowledgment of bushfires as gendered social experiences is a vital first step towards

682 building communities and emergency responders who are more resilient before, during and in

683 the aftermath of disaster.

684

685

686 Acknowledgements:

687 [removed for peer review]

688

689

690

\footnotetext{
${ }^{1}$ All names are pseudonyms.

2 See http://services.land.vic.gov.au/landchannel/content/productCatalogue, accessed 1 June 2015

398 respondents elected to not disclose their gender.

${ }^{4}$ Respondents who indicated 'not applicable' to these two household questions were not counted.
} 
694

695 Allen, P.J. and Bennett, K., 2008: SPSS for the health \& behavioural sciences. Thomson, 696 South Melbourne, VIC.

697

698 Blanchi, R., Leonard, J., Haynes, K., Opie, K., James, M., Dimer de Oliveira, F. 2014:

699 Environmental circumstances surrounding bushfire fatalities in Australia 1901-2011.

700 Environmental Science and Policy 37, 192-203.

701

702

Blanchi, R., Leonard, J., Haynes, K., Opie, K., James, M., Kilinc, M., Dimer de Oliveira, F.,

703 Van den Hornet, R. 2012: Life and house loss database description and analysis. CSIRO,

704 Bushfire CRC report to the Attorney-General's Department. CSIRO EP-129645

705

706 Bradfield, A. and Wells, G.L., 2005: Not the same old hindsight bias: outcome information

707 distorts a broad range of retrospective judgments. Memory \& Cognition 33, 120-130.

708

709 Bryant, L. and Pini, B., 2010: Gender and rurality. Routledge, New York.

710

711 Bryman A., 2008: Social research methods. Oxford University Press, Oxford.

712

713 Campbell, H., Bell, M.M. and Finney, M. (eds), 2006: Country boys: masculinity and rural 714 life. The Pennsylvania State University Press, University Park, PA.

715

716 Country Fire Authority (CFA), 2015: Fire Danger Rating brochure.

717 http://www.cfa.vic.gov.au/fm_files/attachments/warnings_and_restrictions/fire_danger_rating 
.pdf [Verified 1 June 2015]

719

720 Cox, H., 1998: Women in bushfire territory. In Enarson, E. and Morrow, B.H. (eds) The gendered terrain of disaster: through women's eyes. 133-142. Praeger, Westport.

Crompton, R.P., McAneney, K.J., Chen, K., Pielke Jr, A. and Haynes, K., 2010: Influence of location, population and climate on building damage and fatalities due to Australian bushfire: 1925-2009. Weather, Climate and Society 2 (4), 300-310.

726

727

Desmond, M., 2007: On the fireline: living and dying with wildland firefighters. The

University of Chicago Press, Chicago.

Enarson, E., 2012: Women confronting natural disaster: from vulnerability to resilience.

Lynne Rienner Publishers, Inc., Boulder, CO.

Eriksen, C., 2014a: Gender and wildfire: landscapes of uncertainty. New York, Routledge.

735 Eriksen, C., 2014b: Gendered risk engagement: challenging the embedded vulnerability,

736 social norms and power relations in conventional Australian bushfire education.

737 Geographical Research 52, 23-33.

738

739 Eriksen, C., Gill, N. and Head, L., 2010: The gendered dimensions of bushfire in changing

740 rural landscapes in Australia. Journal of Rural Studies 26, 332-342.

742 Haynes, K., Handmer, J., McAneney, J., Tibbits, A. and Coates, L., 2010: Australian bushfire 
743 fatalities 1900-2008: exploring trends in relation to the 'Prepare, stay and defend or leave

744 early' policy. Environmental Science and Policy 13, 185-194.

745

746 Hoffman, S.M., 1998: Eve and Adam among the embers: gender patterns after the Oakland

747 Berkeley firestorm. In Enarson, E. and Morrow, B.H. (eds) The Gendered Terrain of

748 Disaster: Through Women's Eyes. 55-61. Praeger, Westport.

749

750 Karoly, D.J., 2009: The recent bushfires and extreme heat wave in southeast Australia.

751 Bulletin of the Australian Meteorological and Oceanographic Society 22, 10-13.

752

753 Kelle, U., 2007: The development of categories: different approaches in grounded theory. In

754 Bryant, A. and Charmaz, K. (eds) The SAGE handbook of grounded theory. 191-213. Sage

755 Publications, Los Angeles.

756

757 McLennan, J., Elliott, G., Omodei, M. and Whittaker, J., 2013: Householders’ safety-related

758 decisions, plans, actions and outcomes during the 7 February 2009 Victorian (Australia)

759 wildfires. Fire Safety Journal 61, 175-184.

760

761 Moncrief, M., 2009: 'Worst day in history': Brumby warns of fire danger. The

762 Age, 6 February 2009. Available at http://www.theage.com.au/national/worst-day-in-history-

763 brumby-warns-of-fire-danger-20090206-7zf1.html [Verified 1 June 2015]

764

765 Pacholok, S., 2013: Into the fire: disaster and the remaking of gender. University of Toronto

766 Press, Toronto.

767 
768 Parkinson, D., 2011: The way he tells it: relationships after Black Saturday. Women's Health

769 Goulburn North East, Wangaratta, VIC.

770

771 Parkinson, D. and Zara, C., 2011: Beating the flames: women escaping and surviving Black

772 Saturday. Women's Health Goulburn North East, Wangaratta, VIC.

773

774 Pease, B., 2010: Undoing privilege: unearned advantage in a divided world. Zed Books, 775 London.

776

777 Proudley, M., 2008a: Fire, families and decisions. The Australian Journal of Emergency

$778 \quad$ Management $23(1), 37-43$.

779

780 Proudley, M., 2008b: Fire, families and decisions. Unpublished thesis. RMIT University,

781 Melbourne.

782

783 Teague, B., McLeod, R. and Pascoe, S., 2010: 2009 Victorian Bushfires Royal Commission

784 final report: summary. Available at

785 http://www.royalcommission.vic.gov.au/finaldocuments/summary/HR/VBRC_Summary_HR.

786 pdf [Verified 1 June 2015]

787

788 Tyler, M. and Fairbrother, P., 2013: Bushfires are men's business: the importance of gender

789 and rural hegemonic masculinity. Journal of Rural Studies 30, 110-119.

790

791 Whittaker, J., McLennan, J., Elliot, G., Gilbert, J., Handmer, J., Haynes, K. and Cowlishaw,

792 S., 2009a: Victorian 2009 Bushfire Research Response: final report. Available at 
793 http://www.bushfirecrc.com/sites/default/files/managed/resource/bushfire-crc-victorian-fires-

794 research-taskforce-final-report.pdf [Verified 1 June 2015]

795

796 Whittaker, J., Haynes, K., McLennan, J., Handmer, J. and Towers, B., 2009b: Victorian 2009

797 Bushfire Research Response: household mail survey. Available at

798 http://www.bushfirecrc.com/sites/default/files/managed/resource/bushfire-crc-housholder-

799 mail-survey-executive-summary-10-1-10.pdf [Verified 1 June 2015]

800

801 Whittaker, J., Haynes, K., Handmer, J. and McLennan, J., 2013a: Community safety during

802 the 2009 Australian ‘Black Saturday' bushfires: an analysis of household preparedness and

803 response. International Journal of Wildland Fire 22, 841-849.

804

805 Whittaker, J., Handmer, J. and Karoly, D., 2013b: After 'Black Saturday': adapting to

806 bushfires in a changing climate. In Palutikof, J., Karoly, D., Boulter, S. and Guitart, D. (eds)

807 Natural disasters and adaptation to climate change. 75-86. Cambridge University Press,

808 Melbourne.

809 


\section{0}

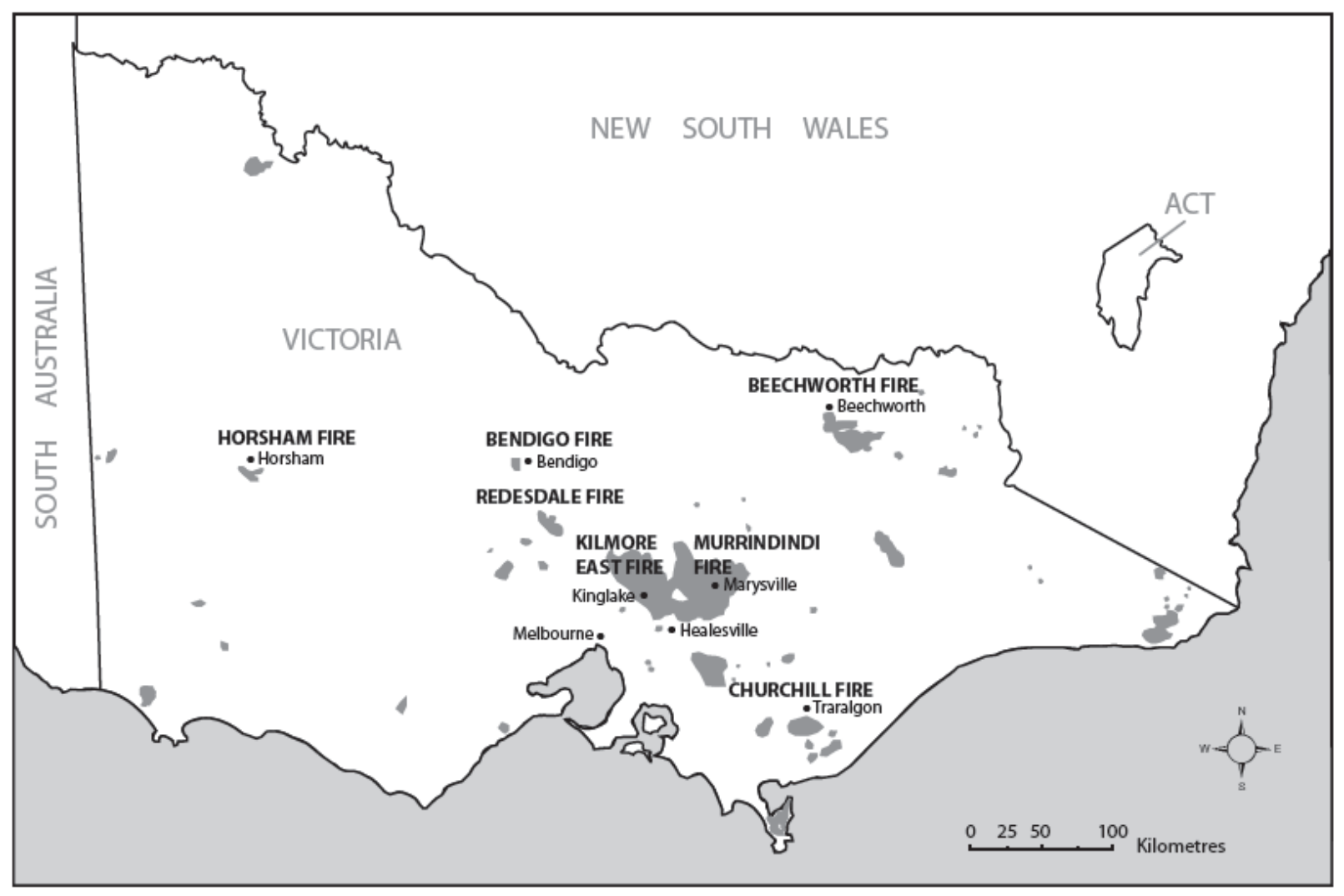

811

812 Figure 1: Areas of Victoria affected by bushfires during January and February 2009 (shaded 813 dark grey) 


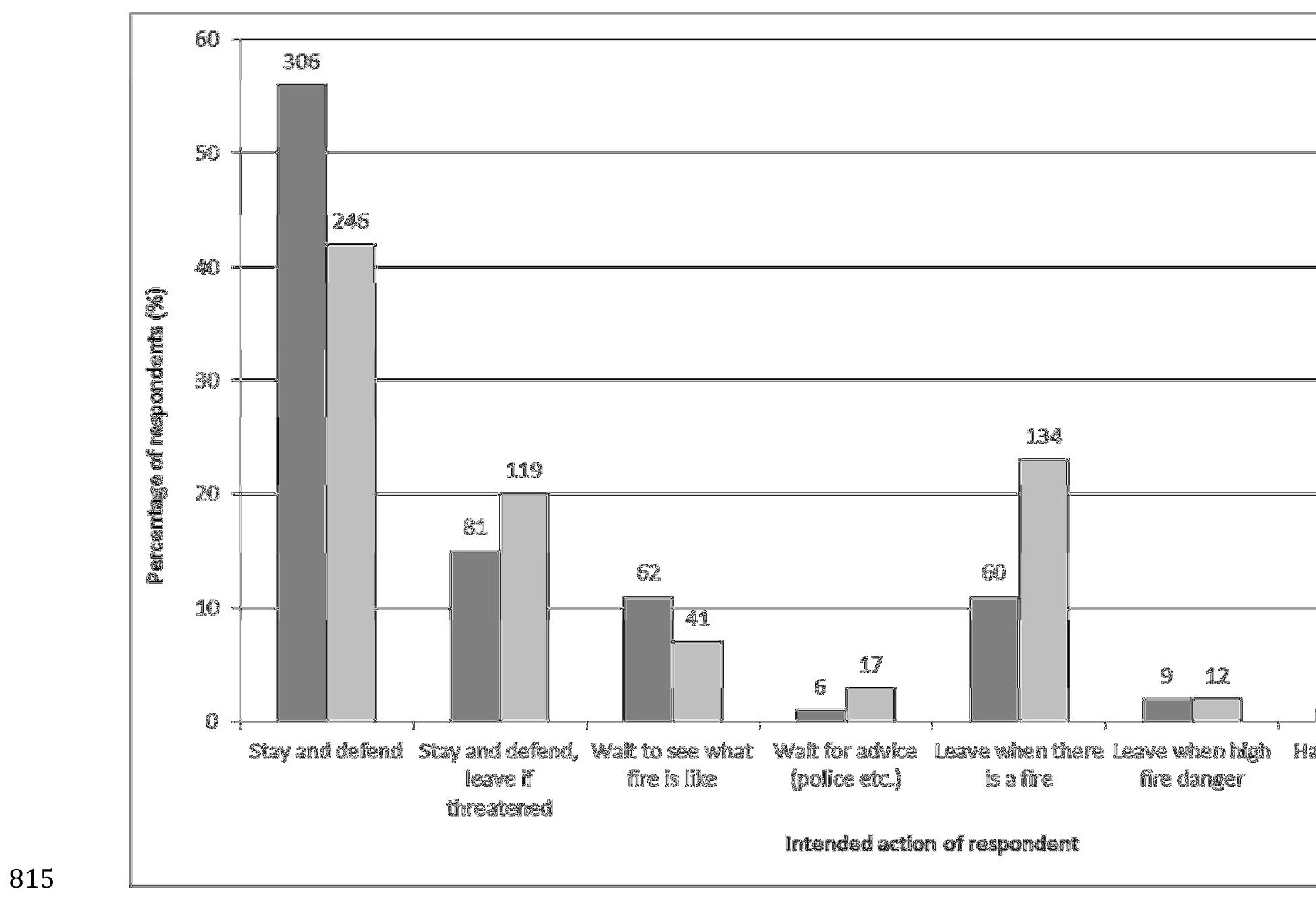

816

817 Figure 2: Intended responses of residents threatened by the 2009 Black Saturday bushfires.

818 Data labels indicate raw numbers.

819 


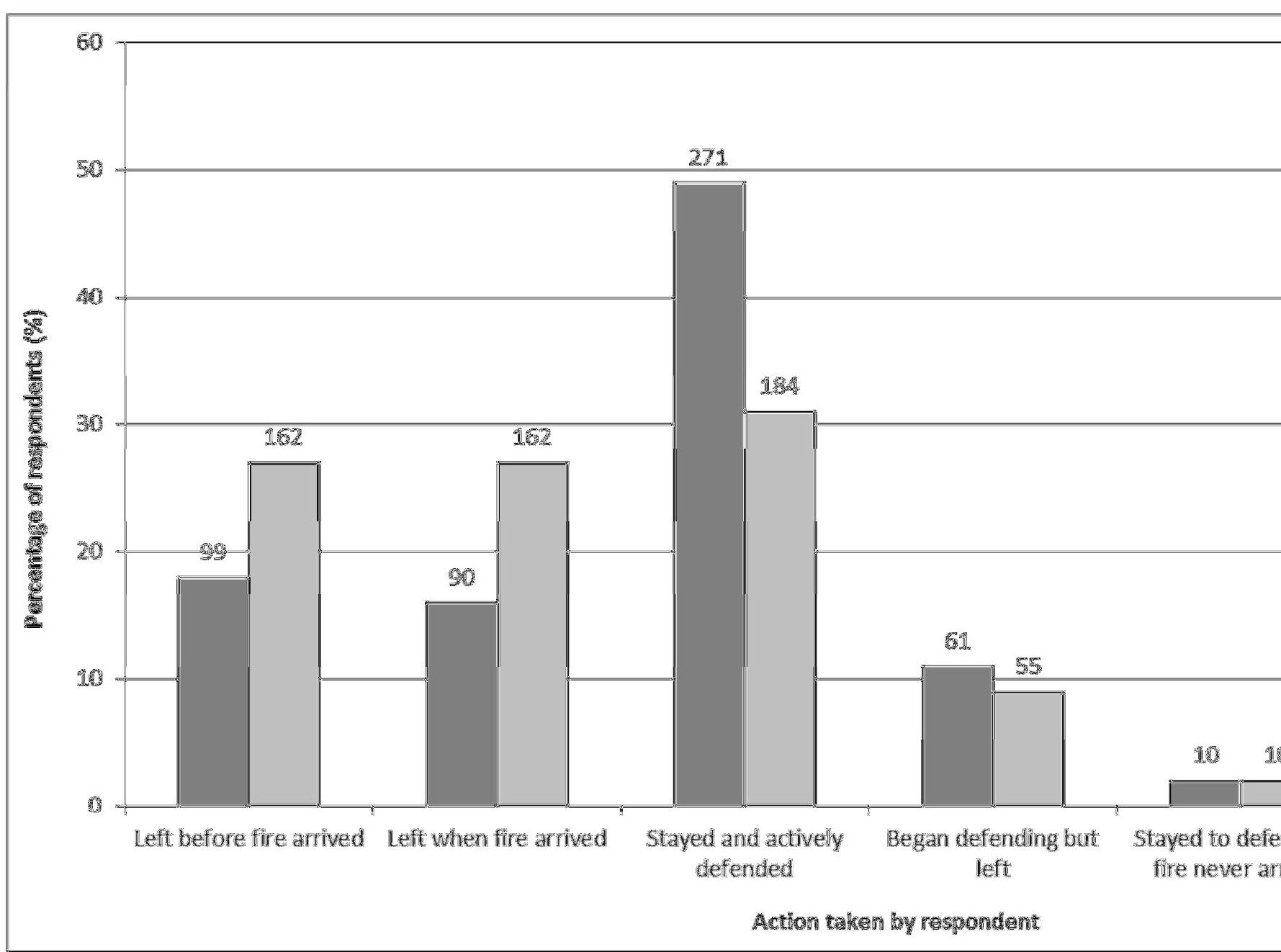

821

822 Figure 3: Action taken by residents during the 2009 Black Saturday bushfires. Data labels

823 indicate raw numbers. 